Note

\title{
Fate of Elevated L-Tryptophan in the Blood of Nephrotic Rats with Oral L-Tryptophan Administration in Their Body
}

\author{
Emi SASAKI ${ }^{1}$ and Yoshiji OHTA ${ }^{2, *}$ \\ ${ }^{1}$ Department of Biochemistry, and ${ }^{2}$ Department of Chemistry, School of Medicine, Fujita Health University, \\ Toyoake, Aichi 470-1192, Japan
}

(Received March 9, 2005)

\begin{abstract}
Summary We examined the changes in serum, liver, kidney, brain, and muscle L-tryptophan (Trp) levels in rats with puromycin aminonucleoside (PAN) nephrosis following oral Trp administration in order to elucidate the fate of elevated Trp in the blood of PAN nephrotic rats with oral Trp administration in their body. Before administration, nephrotic rats had higher liver and kidney Trp contents and lower serum Trp concentration than nonnephrotic rats. At $15 \mathrm{~min}$ after oral administration of $\operatorname{Trp}(100 \mu \mathrm{mol} / \mathrm{kg}$ body weight), PAN nephrotic rats had a much higher amount of liver Trp than non-nephrotic rats but there were no differences in increased amounts of serum, kidney, brain, and muscle Trp between the two groups. At 30 min after oral Trp administration, PAN nephrotic rats had a lower increased amount of serum Trp than non-nephrotic rats and had no increase in liver Trp content, although the increased amounts of Trp in other tissues were similar in both groups. At $30 \mathrm{~min}$ after oral Trp administration, liver tryptophan 2,3-dioxygenase activity increased approximately 2 fold in PAN nephrotic rats. These results indicate that elevated Trp in the blood of PAN nephrotic rats with oral Trp administration is transported mainly into the liver rapidly and then the transported Trp is actively metabolized by activated tryptophan 2,3dioxygenase in the tissue.
\end{abstract}

Key Words puromycin aminonucleoside nephrosis, serum and tissue L-tryptophan, tryptophan 2,3-dioxygenase, L-tryptophan administration

L-Tryptophan (Trp) is one of the nutritionally essential amino acids. Under physiological conditions, more than $90 \%$ of total plasma Trp is known to be converted to kynurenine and subsequently to NAD and acetyl $\mathrm{CoA}$ in the liver through the kynurenine pathway in which tryptophan 2,3-dioxygenase (TDO) participate (1). The remaining Trp is available for protein synthesis in a variety of tissues and for serotonin synthesis in the brain (1). Unlike other amino acids, $80-90 \%$ of the total Trp present in the plasma or serum of humans and animals normally occurs in an albumin-bound form, while the remainder circulates in an albumin-unbound form, i.e., a free form (2-9).

The serum levels of albumin and total Trp are known to decrease in children with nephrosis $(10,11)$. Puromycin aminonucleoside (PAN) is well known to induce nephrosis resembling minimal change nephropathy with focal segmental glomerulosclerosis seen in humans $(12,13)$. We have shown in rats treated once with PAN that the changes in the serum concentrations of total, albumin-bound, and free Trp are closely related to the severity of nephrosis and that total serum Trp concentration is reduced with an increase in free serum Trp concentration under nephrotic conditions in which

\footnotetext{
${ }^{*}$ Corresponding author.

E-mail: yohta@fujita-hu.ac.jp
}

decreased concentrations of albumin and increased concentrations of non-esterified fatty acids (NEFA), which inhibits the binding of Trp to albumin, occur in the serum $(7,8)$. We have also shown in rats with PAN nephrosis that Trp is accumulated in the liver and kidney without being excreted into the urine (7). Furthermore, we have shown that elevated Trp in the blood of PAN nephrotic rats with oral Trp administration disappears more rapidly than that in normal rats without nephrosis under the same intestinal absorption of the administered Trp, and have suggested that this rapid disappearance of elevated Trp in the blood is due to decreased serum albumin concentration $(8,9)$. However, the fate of elevated Trp in the blood of PAN nephrotic rats with oral Trp administration in their body is still unclear.

We, therefore, examined the changes in serum, liver, kidney, brain, and muscle Trp levels and liver TDO activity in rats with and without PAN nephrosis following oral Trp administration in order to elucidate the fate of elevated Trp in the blood of PAN nephrotic rats with oral Trp administration in their body.

\section{Materials and Methods}

Male Wistar rats aged $5 \mathrm{wk}$, which were purchased from Nippon SLC Co. (Hamamatsu, Japan) and maintained on normal rat chow, Oriental MF (Oriental Yeast 
Co., Tokyo, Japan) and tap water were used in the present study. Five animals lived in one stainless steelwired cage. Rats were once intraperitoneally injected with a $1.0 \%(\mathrm{w} / \mathrm{v})$ solution of PAN (Sigma Chemical Co., St. Louis, MO, USA) in $0.85 \% \mathrm{NaCl}$ at a dose of $100 \mathrm{mg} / \mathrm{kg}$ body weight. PNA-untreated rats (control) received a single intraperitoneal injection of an equal volume of $0.85 \% \mathrm{NaCl}$. Daily body weight gain and food intake were not checked because these parameters had little effect on the present experiment. At $7 \mathrm{~d}$ after PAN treatment, urine was collected from PAN-treated and untreated rats in individual metabolism cages for $24 \mathrm{~h}$, which was started 9:00 a.m., as described previously (7-9). The conditions of this urine collection had little effect on the present experiment. At $8 \mathrm{~d}$ after PAN injection, PAN-treated and untreated rats received a single oral administration of a Trp solution in $0.85 \% \mathrm{NaCl}$ (10 mM) at a dose of $100 \mu \mathrm{mol} / \mathrm{kg}$ body weight through a stomach tube between 9:00 and 10:00 a.m. The PANtreated and untreated animals were sacrificed under ether anesthesia just before or 15 or 30 min after Trp administration, at which time blood $(0.5 \mathrm{~mL})$ was collected from the inferior vena cava using a disposable plastic syringe $(1.0 \mathrm{~mL})$. This dose of Trp was almost equivalent to the amount ingested from diet containing $20 \%$ Trp per day. The collected blood was pored into a plastic test tube and kept at room temperature for $30 \mathrm{~min}$ and then separated into serum by centrifugation $(3,000 \mathrm{rpm} \times 10 \mathrm{~min})$ at $4^{\circ} \mathrm{C}$. The liver, kidney, brain, and skeletal muscle were removed after collecting the blood. Before removal of the tissues, ice-cold $0.15 \mathrm{M}$ $\mathrm{KCl}$ was infused from the portal vein for $5 \mathrm{~min}$ to remove blood remaining within the tissues, especially the liver. The obtained urine, serum, and tissues were stored at $-80^{\circ} \mathrm{C}$ until use. The animal experiment was approved by the Committee for the Care and Use of Laboratory Animals in our university.

Protein in the collected urine was measured by the method of Lowry et al. (14) using bovine serum albumin as a standard, as described previously (7-9). Serum albumin was measured using a commercial kit, Albumin B test Wako, based on the bromcresol green method of Doumas et al. (15). Serum NEFA was mea- sured using a commercial kit, NEFA C Test Wako (Wako Pure Chemical Industries, Ltd., Osaka, Japan), based on the enzymatic method. Trp in the collected serum (total and free) and tissues was measured by the high-performance liquid chromatographic method with electrochemical detection as described previously (5-9). The preparation of samples for determination of total and free Trp in serum was carried out using an untrafiltration membrane of Ultrafree C3TK (Millipore Co., Tokyo, Japan) as described previously (6-9). In order to estimate the ratio of albumin-bound Trp (bound Trp) concentration to total Trp concentration in serum, bound serum Trp concentration was calculated by subtracting free serum Trp concentration determined from total serum Trp concentration determined. Liver TDO in a holo type was assayed in the presence of $2 \mu \mathrm{M}$ hematin at $37^{\circ} \mathrm{C}$ under agitation in air according to the method of Metzler et al. (16). One unit of this enzyme activity is defined as the amount of enzyme producing $1 \mu \mathrm{mol}$ kynurenine per hour.

All values obtained are expressed as means \pm SD. Data were analyzed by one-way analysis of variance (oneway ANOVA) and Fisher's protected least significance difference (PLSD) for multiple comparisons as the post hoc test using a computerized statistical package (StatView) . The level of significance was set at $p<0.05$.

\section{Results and Discussion}

For PAN nephrotic rats $(n=15)$ used, protein content in daily urine, and serum albumin and NEFA concentrations were $222 \pm 29 \mathrm{mg} / \mathrm{d}, 2.39 \pm 0.25 \mathrm{~g} / 100 \mathrm{~mL}$, and $917 \pm 105 \mu \mathrm{Eq} / \mathrm{L}$, respectively, at $8 \mathrm{~d}$ after PAN treatment. For non-nephrotic rats $(n=15)$ used, protein content in daily urine, and serum albumin and NEFA concentrations were $8 \pm 2 \mathrm{mg} / \mathrm{d}, 3.54 \pm 0.19 \mathrm{~g} / 100 \mathrm{~mL}$, and $1,286 \pm 176 \mu \mathrm{Eq} / \mathrm{L}$, respectively, at the same time point after PAN treatment done in the nephrotic group.

When the changes in total and free Trp concentrations and the ratio of bound Trp concentration to total Trp concentration before and after oral Trp administration were examined in the serum of PAN nephrotic and non-nephrotic rats, the results shown in Table 1 were obtained. Just before Trp administration, total serum

Table 1. Time courses of Trp levels and the binding ratio of Trp to albumin in sera of PAN nephtrotic and non-nephrotic rats with oral Trp administration.

Trp administration

\begin{tabular}{|c|c|c|c|c|c|c|}
\hline & \multicolumn{2}{|c|}{ Before } & \multicolumn{2}{|c|}{$15 \mathrm{~min}$} & \multicolumn{2}{|c|}{$30 \mathrm{~min}$} \\
\hline & -Nephross & +Nephrosis & -Nephrosis & + Nephrosis & -Nephrosis & +Nephrosis \\
\hline Total Trp $(\mathrm{nmol} / \mathrm{mL})$ & $109.8 \pm 7.8$ & $45.5 \pm 5.9^{*}$ & $234.1 \pm 37.7^{\S}(124.3)$ & $158.0 \pm 9.9^{* \# \#}(112.5)$ & $190.9 \pm 14.4^{\S}(80.2)$ & $73.9 \pm 22.6^{*, \#}(28.4)$ \\
\hline Free Trp $(\mathrm{nmol} / \mathrm{mL})$ & $10.8 \pm 0.7$ & $24.5 \pm 5.5^{*}$ & $54.6 \pm 11.2^{\S}(43.8)$ & $83.1 \pm 24.6^{*, \#}(58.6)$ & $32.6 \pm 6.2^{\S}(21.8)$ & $45.4 \pm 8.5^{*, \#}(20.9)$ \\
\hline Bound Trp/total Trp (\%) & $90.1 \pm 0.3$ & $46.2 \pm 11.9^{*}$ & $76.8 \pm 1.8^{\S}$ & $47.4 \pm 12.6^{*}$ & $83.1 \pm 4.3^{\S}$ & $38.6 \pm 4.8^{*}$ \\
\hline
\end{tabular}

Each value is a mean \pm SD ( $n=5$ for each group). Values in parenthesis represent the differences in mean serum Trp concentrations determined before and after Trp administration. *Significantly different from the corresponding non-nephrotic rats at $p<0.05$. ${ }^{\S}$ Significantly different from non-nephrotic rats before Trp administration at $p<0.05$. \#Significantly different from PAN nephrotic rats before Trp administration at $p<0.05$. 
Table 2. Time courses of liver, kidney, brain, and muscle Trp contents in PAN nephrotic and non-nephrotic rats with oral Trp administration.

\begin{tabular}{|c|c|c|c|c|c|c|}
\hline & \multicolumn{6}{|c|}{ Trp administration } \\
\hline & \multicolumn{2}{|c|}{ Before } & \multicolumn{2}{|c|}{$15 \mathrm{~min}$} & \multicolumn{2}{|c|}{$30 \mathrm{~min}$} \\
\hline & -Nephrosis & +Nephrosis & -Nephrosis & + Nephrosis & -Nephrosis & +Nephrosis \\
\hline Liver Trp (nmol/g tissue) & $35.8 \pm 3.8$ & $43.1 \pm 3.0^{*}$ & $47.5 \pm 7.8^{\S}(11.7)$ & $103.8 \pm 14.4^{*, \#}(60.7)$ & $43.1 \pm 3.0^{\S}(7.3)$ & $41.9 \pm 3.5(-1.2)$ \\
\hline Kidney Trp (nmol/g tissue) & $66.0 \pm 6.1$ & $93.4 \pm 3.4^{*}$ & $89.0 \pm 8.6^{\S}(23.0)$ & $113.9 \pm 10.0^{*, \#}(20.5)$ & $83.6 \pm 6.5^{\S}(17.6)$ & $117.5 \pm 11.8^{*, \#}(24.1)$ \\
\hline Brain Trp (nmol/g tissue) & $26.3 \pm 2.4$ & $25.5 \pm 1.9$ & $45.2 \pm 4.8^{\S}(18.9)$ & $48.5 \pm 3.5^{\#}(23.0)$ & $46.7 \pm 3.5^{\S}(20.4)$ & $49.1 \pm 4.3^{\#}(23.6)$ \\
\hline Muscle Trp (nmol/g tissue) & $32.2 \pm 4.5$ & $27.2 \pm 5.2$ & $52.9 \pm 9.9^{\S}(20.7)$ & $47.3 \pm 7.1^{\#}(20.1)$ & $53.6 \pm 6.8^{\S}(21.4)$ & $50.5 \pm 9.8^{\#}(23.3)$ \\
\hline
\end{tabular}

Each value is a mean \pm SD ( $n=5$ for each group). Values in parenthesis represent the differences in mean tissue Trp contents determined before and after Trp administration. *Significantly different from the corresponding non-nephrotic rats at $p<0.05$. ${ }^{\S}$ Significantly different from non-nephrotic rats before Trp administration at $p<0.05$. \#Significantly different from PAN nephrotic rats before Trp administration at $p<0.05$.

Trp concentration in the nephrotic group was $41.4 \%$ of that in the non-nephrotic group, while free serum Trp concentration in the nephrotic group was 2.3-fold higher than that in the non-nephrotic group. At $15 \mathrm{~min}$ after oral administration of Trp $(100 \mu \mathrm{mol} / \mathrm{kg}$ body weight), total and free serum Trp concentrations increased significantly in the nephrotic and non-nephrotic groups, but the increased amount of free serum Trp was 1.3-fold larger in the nephrotic group than in the non-nephrotic group although the increased amount of total serum Trp was almost equal in both groups. At $30 \mathrm{~min}$ after oral Trp administration, total and free serum Trp concentrations significantly increased in both the nephrotic and non-nephrotic groups, but the increased amount of total serum Trp in the nephrotic group was 35\% of that in the non-nephrotic group and the increased amount of free serum Trp was almost equal in both groups. The ratio of bound serum Trp concentration to total serum Trp concentration was significantly lower in the nephrotic group than in the non-nephrotic group just before and at 15 and $30 \mathrm{~min}$ after oral Trp administration. These results indicate that the rate of disappearance of elevating Trp in the blood of PAN nephrotic rats with oral Trp administration is much faster than that in non-nephrotic rats with the same Trp administration.

When the changes in liver, kidney, brain, and muscle Trp contents before and after oral Trp administration were examined in PAN nephrotic and non-nephrotic rats, the results shown in Table 2 were obtained. Liver and kidney Trp contents were significantly higher in the nephrotic group than in the non-nephrotic group just before Trp administration. At $15 \mathrm{~min}$ after oral administration of Trp $(100 \mu \mathrm{mol} / \mathrm{kg}$ body weight $)$, Trp content increased significantly in the liver, kidney, brain, and muscle of the nephrotic and non-nephrotic groups, and the increased amount of liver Trp (a mean value, $60.5 \mathrm{nmol} / \mathrm{g}$ tissue) in the nephrotic group was 5.2 -fold larger than that (a mean value, $11.7 \mathrm{nmol} / \mathrm{g}$ tissue) in the non-nephrotic group, although the increased amounts of Trp in the kidney, brain, and muscle were similar in both groups. At 30 min after oral Trp admin- istration, a significant increase in Trp content occurred in the kidney, brain, and muscle of the nephrotic and non-nephrotic groups and in the liver of the non-nephrotic group, although the increased amounts of kidney, brain, and muscle Trp were not significantly different between the nephrotic and non-nephrotic groups. However, the nephrotic group had no increase in liver Trp content at $30 \mathrm{~min}$ after oral Trp administration and the liver Trp content in the nephrotic group was almost equal to that in the non-nephrotic group. Thus, a transient, marked increase in liver Trp content during 30 min after Trp administration occurred in rats with PNA nephrosis. These results indicate that elevated blood Trp in PAN nephrotic rats with oral Trp administration is transported mainly into the liver rapidly, although the elevating Trp in the blood is transported to other tissues such as the kidney, brain, and muscle in an extent similar to non-nephrotic rats. These results also suggest a possibility that Trp transported into the liver of PAN nephrotic rats after oral Trp administration is actively metabolized in the tissue.

Next, we examined whether Trp transported into the liver of PAN nephrotic rats after oral Trp administration is actively metabolized in the tissue. Under physiological conditions, more than $90 \%$ of Trp present in plasma is taken up into the liver and then metabolized to NAD and acetyl CoA via the kynurenine pathway in which TDO takes part (1). TDO is not only the first enzyme in the liver Trp metabolic pathway but also the rate-limiting enzyme in that metabolism (1). There was no difference in liver TDO activity between rats with and without PAN nephrosis just before and at $15 \mathrm{~min}$ after oral administration of Trp $(100 \mu \mathrm{mol} / \mathrm{kg}$ body weight (Table 3). At $30 \mathrm{~min}$ after Trp administration, PAN nephrotic rats had a 2.1-fold higher liver TDO activity than non-nephrotic rats (Table 3). The Km of purified rat liver TDO is from 0.1 to $0.4 \mathrm{mM}$ Trp (17). The mean Trp content in the liver of PAN nephrotic rats at $15 \mathrm{~min}$ after Trp administration was $103.8 \mathrm{nmol} / \mathrm{g}$ tissue. The liver Trp concentration is estimated to be about $0.1 \mathrm{~mm}$ if $1 \mathrm{~g}$ of the wet liver tissue is equivalent to $1 \mathrm{~mL}$. These results suggest that, in PAN nephrotic rats with oral Trp 
Table 3. Time course of liver TDO activity in PAN nephrotic and non-nephrotic rats with oral Trp administration.

\begin{tabular}{lccc}
\hline & \multicolumn{3}{c}{ Trp administration } \\
\hline & Before & 15 min & $30 \mathrm{~min}$ \\
\hline \multicolumn{4}{c}{ TDO activity (units/g tissue) } \\
\hline Non-nephrotic rats & $3.81 \pm 0.99$ & $4.89 \pm 1.19$ & $4.58 \pm 0.83$ \\
Nephrotic rats & $4.19 \pm 0.26$ & $5.46 \pm 0.64$ & $8.94 \pm 2.09^{*, \#}$
\end{tabular}

Each value is a mean \pm SD ( $n=5$ for each group). *Significantly different from the corresponding non-nephrotic rats at $p<0.05$. \#Significantly different from PAN nephrotic rats before Trp administration at $p<0.05$.

administration, administered Trp is actively metabolized via TDO being activated in the liver after its transport into the tissue. This phenomenon seems to be relevant to the maintenance of liver Trp at its physiological level in PAN nephrotic rats by preventing accumulation of a large amount of the amino acid in the liver. Donner and Kröger (18) have shown in rats administered with Trp at doses of more than $12.5 \mathrm{mg} / \mathrm{kg}$ body weight, i.e., $61.3 \mu \mathrm{mol} / \mathrm{kg}$ body weight that TDO induction occurs in the liver and that this induction of liver TDO is due to the ability of Trp to stabilize the enzyme. The dose of Trp administered to PAN nephrotic rats in the present study was $100 \mu \mathrm{mol} / \mathrm{kg}$ body weight. Therefore, a similar mechanism seems to be applicable to the activation of TDO found in the liver of PAN nephrotic rats with oral Trp administration, because a rapid, marked increase in liver Trp content occurred in the Trp-administered nephrotic rats, as described above. Lewandowski et al. (19) have shown in PAN nephrotic rats that the rate of synthesis of albumin and other plasma proteins is markedly increased in the liver. Therefore, one can think that Trp administered to PAN nephrotic rats is actively utilized for synthesis of plasma proteins in the liver after its transport into the tissue. In addition, there seems to be a possibility that, in the liver of PAN nephrotic rats, the rate of Trp uptake is stimulated in response to a marked increase in synthesis of plasma proteins. Thus, besides hepatic Trp metabolism via activated TDO, several factors may contribute to the fate of elevated Trp in the blood of PAN nephrotic rats with oral Trp administration in their body.

In conclusion, the results of the present study indicate that elevated Trp in the blood of PAN nephrotic rats with oral Trp administration is transported mainly into the liver rapidly, although the elevated blood Trp was transported into other tissues, such as kidney, muscle, and brain, and then the Trp transported into the liver is actively metabolized by activated TDO in the tissue.

\section{REFERENCES}

1) Bender DA. 1982. Biochemistry of tryptophan in health and disease. Mol Aspects Med 6: 101-109.
2) McMenamy RH, Lund CC, Oncley JL. 1957. Unbound amino acid concentration in human blood plasma. J Clin Invest 36: 1672-1679.

3) McNenamy RH, Oncley JL. 1958. The specific binding of L-tryptophan to serum albumin. I Biol Chem 233: 1436-1447.

4) Fuller S, Roush BW. 1973. Binding of tryptophan to plasma proteins in several species. Comp Biochem Physiol 46B: 273-276.

5) Saito K, Sasaki E, Ohta Y, Nagamura Y, Ishiguro I. 1986. Mode of L-tryptophan uptake into rat hepatocytes via trypsin-sensitive high-affinity transport system. Biochem Int 13: 873-883.

6) Sasaki E, Ohta Y, Shinohara R, Ishiguro I. 1993. Effect of serum fatty acid levels on disappearance of blood Ltryptophan in rats fed lard. J Jpn Soc Nutr Food Sci (Nippon Eiyo Shokuryo Gakkashi) 46: 487-493.

7) Sasaki E, Ohta Y, Shinohara R, Ishiguro I. 1997. Changes of serum L-tryptophan levels following the development and recovery of acute puromycin aminonucleoside nephrosis in rats. Amino Acids 12: 353-361.

8) Sasaki E, Ohta Y, Ishiguro I. 1999. Effect of albumin administration on L-tryptophan levels in the serum and tissues of rats with puromycin aminonucleosideinduced nephrosis. Adv Exp Med Biol 467: 341-346.

9) Sasaki E, Ohat Y, Saito H, Ishiguro I. 1999. Possible contribution of a decrease in serum albumin concentration to a low level of blood L-tryptophan in nephrotic rats. J Nutr Sci Vitaminol 45: 367-374.

10) Pirazzoli G, Casadio L, Rosini R, Gualandi S, Tazzari R, Corsini F. 1983. Studio delle correalazioni fra tritofano, NEFA e albumina nella syndrome nefrosia. Boll Soc Ital Biol Sper 59: 1-7.

11) Fydryk J, Kurzawaska O, Szuba W. 1984. Serum tryptophan (Try) level and its binding capacity to albumin in nephrotic syndrome (SN). Int J Pediat Nephrol 5: 124.

12) Frenk S, Antonowicz I, Craig JM, Metcoff J. 1955. Experimental nephrosis syndrome induced in rats by aminonucleoside. Renal lesions and body electrolyte composition. Proc Soc Exp Biol Med 89: 424-427.

13) Diamond BT, Karnovsky MJ. 1986. Focal and segmental glomerulosclerosis following a single intravenous dose of puromycin aminonucleoside. Am J Pathol 122: 481487.

14) Lowry OH, Rosebrough MJ, Farr AL, Randall RJ. 1951. Protein measurement with the Folin phenol reagent. $J$ Biol Chem 193: 265-275.

15) Doumas BT, Watson A, Biggs HG. 1971. Albumin standards and the measurement of serum albumin with bromcresol green. Clin Chim Acta 31: 87-96.

16) Metzler H, Geharbt R, Mecke Y. 1982. A convenient and highly sensitive spectrophotometric assay for tryptophan 2,3-dioxygenase. Anal Biochem 121: 10-16.

17) Schimke RT. 1970. L-Tryptophan 2,3-dioxygenase (Tryptophan pyrrolase) (Rat liver). Methods Enzymol 17A, 421-428.

18) Donner I, Kröger H. 1976. Effect of substrate and small doses of cortisone on the induction of tryptophan 2,3dioxygenase. Hoppe-Seyler's Z Physiol Chem 357: 811817.

19) Lewandowski AE, Liao WSL, Stinson-Fisher CA, Kent JD, Jefferson LS. 1988. Effects of experimentally induced nephrosis on protein synthesis in rat liver. Am J Physiol 254: C634-C642. 